\title{
A Structural Model for Mixed-Nitrate Ionic Glasses
}

\author{
Z. Akdeniz and M.P. Tosi ${ }^{\mathrm{a}}$ \\ Abdus Salam ICTP, Trieste, Italy and Department of Physics, University of Istanbul, Turkey \\ a Abdus Salam ICTP, Trieste and Classe di Scienze, Scuola Normale Superiore, Pisa, Italy \\ Reprint requests to Prof. M. P. T.; Fax: +39-050-563513; E-mail: tosim@sns.it
}

Z. Naturforsch. 59a, 957 - 960 (2004); received September 13, 2004

\begin{abstract}
We propose and evaluate a structural model for mixed K-Ca nitrate melts and glasses, which invokes the presence of strongly bound $\mathrm{Ca}_{2}\left(\mathrm{NO}_{3}\right)_{7}$ groups surrounded by $\mathrm{K}$ ions that can transport charge by relatively free jumps. To this purpose we first construct ionic models for the pure $\mathrm{ANO}_{3}$ compounds (with $\mathrm{A}=$ alkali metal ion), by searching for suitable $\mathrm{A}^{+Z} \cdot\left(\mathrm{NO}_{3}\right)^{-Z}$ interionic potentials in the space of interionic-law parameters with the help of known models for alkali chlorides. The available evidence mainly consists of infrared-active mode frequencies, and is compatible with two alternative types of interionic parameters. A choice between them is made on the basis of the fact that the $\mathrm{NO}_{3}$ group has a flat triangular shape and can execute torsional oscillations giving rise to a low-frequency Raman-active mode in the melt. This interionic force model is then combined with a similar model for $\mathrm{Ca}\left(\mathrm{NO}_{3}\right)_{2}$ to evaluate the structural properties of a $3 \mathrm{KNO}_{3} \cdot 2 \mathrm{Ca}\left(\mathrm{NO}_{3}\right)_{2}$ unit, which is the constituent of the well-known glassformer CKN. We expect that the present model should be representative of other mixed alkali-divalent ion nitrate systems in the range of concentration where glass formation is observed.
\end{abstract}

Key words: Ionic Glasses; Molten Salts.

\section{Introduction}

Superionic-conducting oxide glasses consist of a network former such as $\mathrm{SiO}_{2}$ or $\mathrm{Al}_{2} \mathrm{O}_{3}$ and a network modifier such as $\mathrm{Na}_{2} \mathrm{O}$ or $\mathrm{Li}_{2} \mathrm{O}$ (for an introductory overview on the glassy state of matter see [1]). The modifier lowers the glass transition temperature and opens up the network structure by introducing nonbridging oxygens, while the alkali ions are mobile and can diffuse through the disordered network. The decoupling of the electrical conduction from shear viscosity modes is apparently quite different from the usual $(\alpha, \beta)$ bifurcation in a glass [2]. The modes associated with the motions of small monovalent cations become anharmonic at temperatures far below those of other species, and these cations can easily escape from their site and wander around through the vitreous structure.

The structural model that we have mentioned above for superionic oxide glasses does not seem to apply, however, to mixed nitrate glasses. The prototype of these systems is the $\mathrm{CKN}$ glass with the chemical formula $\left(\mathrm{KNO}_{3}\right)_{0.6} \cdot\left(\mathrm{Ca}\left(\mathrm{NO}_{3}\right)_{2}\right)_{0.4}$ or $\mathrm{Ca}_{2} \mathrm{~K}_{3}\left(\mathrm{NO}_{3}\right)_{7}$ (see for instance [3]). This compound melts at $T_{m}=498 \mathrm{~K}$, and its glass transition temperature is $T_{g}=333 \mathrm{~K}$, thus obeying the empirical rule $T_{g} \approx 2 T_{m} / 3$. Its transport properties in the melt have been studied in depth over broad temperature ranges, to show that the shear viscosity obeys a universal near-Arrhenius law [4], and that the relationship $\sigma T \propto(T / \eta)^{m}$ between shear viscosity $\eta$ and ionic conductivity $\sigma$ is obeyed over nine orders of magnitude with $m \cong 0.8$ [5]. A nonlinear Stokes-Einstein law evidently is a manifestation of a basic difference in the elementary mechanisms of momentum and charge transport.

More generally, nitrate glasses are formed by mixing the nitrate of a divalent-metal ion (such as $\mathrm{Mg}, \mathrm{Ca}$, or $\mathrm{Cd}$ ) with that of an alkali-metal ion (such as $\mathrm{Na}$ or $\mathrm{K})$ over a fairly broad range of composition around that indicated above for CKN (see for example [6]). The $\mathrm{NO}_{3}$ group is a very stable and chemically saturated unit, in the shape of a planar equilateral triangle with nitrogen at its center [7]. For instance, the frequencies of its internal vibration modes are almost independent of the metal-ion partners in the mixed nitrate glasses [6] and in the molten nitrates of alkali, Ag, and $\mathrm{Tl}$ ions as well [ $8-10]$. The formation of a spatial network of chemical bonds between such groups in a nitrate glass is therefore unlikely. On the other hand, unassisted Coulomb interactions are very ineffective in 
inducing a glass transition [11]. One should thus search for a structural model of nitrate glasses in terms of a frozen disordered array of strongly bound units. Such examples of glass structures are well known among the glass-forming elements: for example, threefold coordination in $\mathrm{P}$ and As yields $\mathrm{P}_{4}$ and $\mathrm{As}_{4}$ tetrahedra as basic units of the crystal and of the glass.

In this work we construct such a structural model for CKN in the molten and the glassy state. We start in Sect. 2 by examining some ionic models for the interactions between the alkali and nitrate ions in alkali nitrates, which may be compatible with the scanty experimental data that are available for this purpose. We find that two alternative models may be proposed, corresponding to markedly different values for the charge transfer from the alkali to the $\mathrm{NO}_{3}$ group and for the size and stiffness of the $\mathrm{NO}_{3}$ group. We choose among these two models on the basis of a known property of the nitrate ions in these compounds: disorder in their orientations has been observed to develop in crystalline $\mathrm{NaNO}_{3}$ in the temperature range 150 to $275{ }^{\circ} \mathrm{C}$ [12], and a low-frequency Raman-active mode has been associated with their rotatory motions in the alkali nitrate melts [10]. We argue that these behaviors favor the ionic model in which the charge transfer is lower and the $\mathrm{NO}_{3}$ group is "thinner" and stiffer (model 2, say). We proceed in Sect. 3 to propose a similar model for $\mathrm{Ca}\left(\mathrm{NO}_{3}\right)_{2}$ and to evaluate the structures that are possible for the $\mathrm{Ca}_{2} \mathrm{~K}_{3}\left(\mathrm{NO}_{3}\right)_{7}$ unit. We show that in model 2 a strongly bound $\mathrm{Ca}_{2}\left(\mathrm{NO}_{3}\right)_{7}$ complex can form, which may be the basic constituent of the mixed-nitrate melts and glasses. Finally, Sect. 4 offers a brief summary and suggests some further developments.

\section{The Alkali Metal Nitrates}

The quantitative evidence which is available for our purposes on alkali nitrates $\mathrm{ANO}_{3}$ mainly consists of the frequency of an infrared-active mode of the melt, which is associated with a vibration of the alkali ion against the $\mathrm{NO}_{3}$ group [10]. We will use these data below to estimate the ionicity of these compounds. Other observational facts can be invoked, however, to help in constructing an interionic force model.

The main relevant facts for our purposes are (i) the strong stability of the $\mathrm{NO}_{3}$ group against changes in its environment; (ii) the $\mathrm{NaCl}$-like arrangement of the alkali and $\mathrm{NO}_{3}$ ions in $\mathrm{ANO}_{3}$ crystals, with some distortions due to the spatial requirements of the complex anions [12]; and (iii) the torsional oscillations
Table 1. Alternative models for the interionic force parameters in alkali nitrates.

\begin{tabular}{lcccccccc}
\hline System & & $Z$ & $\begin{array}{c}R_{\mathrm{A}} \\
(\AA)\end{array}$ & $\begin{array}{c}\rho_{\mathrm{A}} \\
(\AA)\end{array}$ & $\begin{array}{c}R_{\mathrm{X}} \\
(\AA)\end{array}$ & $\begin{array}{c}\rho_{\mathrm{X}} \\
(\AA)\end{array}$ & $\begin{array}{c}r_{\mathrm{A}-\mathrm{N}} \\
(\AA)\end{array}$ & $\begin{array}{c}v_{\text {ir }} \\
\left(\mathrm{cm}^{-1}\right)\end{array}$ \\
\hline $\mathrm{LiNO}_{3}$ & 1 & 0.67 & 0.82 & 0.072 & 1.67 & 0.24 & 2.32 & 350 \\
& 2 & 0.42 & 0.82 & 0.072 & 1.44 & 0.078 & 2.32 & 350 \\
$\mathrm{NaNO}_{3}$ & 1 & 0.84 & 1.17 & 0.14 & 1.67 & 0.24 & 2.54 & 215 \\
& 2 & 0.59 & 1.17 & 0.14 & 1.44 & 0.078 & 2.60 & 215 \\
$\mathrm{KNO}_{3}$ & 1 & 0.92 & 1.46 & 0.18 & 1.67 & 0.24 & 2.80 & 170 \\
& 2 & 0.68 & 1.46 & 0.18 & 1.44 & 0.078 & 2.88 & 170 \\
$\mathrm{RbNO}_{3}$ & 1 & 0.82 & 1.59 & 0.20 & 1.67 & 0.24 & 3.10 & 110 \\
& 2 & 0.61 & 1.59 & 0.20 & 1.44 & 0.078 & 3.10 & 110 \\
$\mathrm{CsNO}_{3}$ & 1 & 0.86 & 1.72 & 0.22 & 1.67 & 0.24 & 3.23 & 100 \\
& 2 & 0.64 & 1.72 & 0.22 & 1.44 & 0.078 & 3.23 & 100 \\
\hline
\end{tabular}

that the $\mathrm{NO}_{3}$ group can carry out in the crystal and in the melt $[10,12]$. These facts are compatible with the assumption that the structural unit of the condensed states of $\mathrm{ANO}_{3}$ compounds may be a trigonal pyramid having the $\mathrm{NO}_{3}$ group as its base and the alkali ion at its apex. In a first approximation this may be described as an $\mathrm{A}^{+Z} \cdot\left(\mathrm{NO}_{3}\right)^{-Z}$ unit bound by rigid-ion interactions, thus neglecting the electrical and short-range polarizabilities of the $\mathrm{NO}_{3}$ ion as well as van der Waals interactions.

We therefore adopt interionic pair potentials to construct the potential energy $U\left(\left\{r_{i j}\right\}\right)$ of a molecular cluster as a function of the set of bond lengths $r_{i j}$ between pairs of ions [13]. We write

$$
U\left(\left\{r_{i j}\right\}\right)=\sum_{i \neq j}\left[\frac{Z_{i} Z_{j}}{r_{i j}}+\Phi_{i j}\left(r_{i j}\right)\right],
$$

where $Z_{i}$ are the ionic valences and $\Phi_{i j}(r)$ are the overlap repulsive potentials. These are taken in the Busing form

$$
\Phi_{i j}(r)=f\left(\rho_{i}+\rho_{j}\right) \exp \left[\left(R_{i}+R_{j}-r\right) /\left(\rho_{i}+\rho_{j}\right)\right],
$$

where $R_{i}$ are the ionic radii, $\rho_{i}$ the ionic inversestiffness constants, and $f=0.05 e^{2} / \AA^{2}$.

As a first step we fix the repulsive parameters for the alkali ions by taking $R_{\mathrm{A}}$ as the Tosi-Fumi radii [14] and by determining $\rho_{\mathrm{A}}$ from a fit of the bond lengths in diatomic alkali chloride molecules [15]. These values are shown in the third and fourth column of Table 1.

Our next task is to assess values for the repulsive parameters of the $\mathrm{X}=\mathrm{NO}_{3}$ ion as seen from the alkali ion. The $\mathrm{Rb}-\mathrm{N}$ distance in $\mathrm{RbNO}_{3}$ is given as $r_{\mathrm{Rb}-\mathrm{N}}=3.10 \AA$ [16], which is not far from what one could crudely estimate from the $\mathrm{N}-\mathrm{O}$ bond length of $1.2 \AA$ in $\mathrm{ANO}_{3}$ crystals [12] and from the sum of the $\mathrm{Rb}^{+}$and $\mathrm{O}^{2-}$ ionic radii $(\approx 3 \AA)$. This suggests that 
Table 2. Best choice for the interionic force parameters in alkali nitrates and calculated values of the bond length $r_{\mathrm{A}-\mathrm{N}}$ and the infrared-mode frequency $v_{i r}$.

\begin{tabular}{lccccccc}
\hline System & $Z$ & $R_{\mathrm{A}}(\AA)$ & $\rho_{\mathrm{A}}(\AA)$ & $R_{\mathrm{X}}(\AA)$ & $\rho_{\mathrm{X}}(\AA)$ & $r_{\mathrm{A}-\mathrm{N}}(\AA)$ & $v_{\text {ir }}\left(\mathrm{cm}^{-1}\right)$ \\
\hline $\mathrm{NaNO}_{3}$ & 0.63 & 1.17 & 0.14 & 1.44 & 0.078 & 2.57 & 230 \\
$\mathrm{KNO}_{3}$ & 0.63 & 1.46 & 0.18 & 1.44 & 0.078 & 2.92 & 155 \\
$\mathrm{RbNO}_{3}$ & 0.63 & 1.59 & 0.20 & 1.44 & 0.078 & 3.08 & 115 \\
$\mathrm{CsNO}_{3}$ & 0.63 & 1.72 & 0.22 & 1.44 & 0.078 & 3.24 & 98 \\
\hline
\end{tabular}

the structure of the $\mathrm{A}^{+Z} \cdot\left(\mathrm{NO}_{3}\right)^{-Z}$ unit is determined by the near-contact between the alkali ion and the oxygen ions, the $\mathrm{N}$ ion being extremely small [17] and being therefore screened by its oxygen partners in the $\mathrm{NO}_{3}$ group. The aforementioned value of the $\mathrm{Rb}-\mathrm{N}$ bond length can then be used to estimate the ionic radius $R_{\mathrm{X}}$ of the $\mathrm{NO}_{3}$ group from a given assumed value of the ratio $R_{\mathrm{X}} / \rho_{\mathrm{X}}$. We have assumed two alternative values for the above ratio, the first $\left(R_{\mathrm{X}} / \rho_{\mathrm{X}} \approx 6.9\right.$, denoted as model 1) being appropriate for a soft spherical anion such as $\mathrm{Cl}^{-}$, and the second $\left(R_{\mathrm{X}} / \rho_{\mathrm{X}} \approx 18.6\right.$, model 2$)$ for a stiffer divalent ion [18]. We believe that the latter choice is more appropriate to describe the overlap repulsion between an alkali ion and the flat $\mathrm{NO}_{3}$ group executing torsional oscillations in the trigonal-pyramid structure that we are assuming for the $\mathrm{A}^{+Z} \cdot\left(\mathrm{NO}_{3}\right)^{-Z}$ unit, while the former choice would become appropriate if the $\mathrm{NO}_{3}$ group were a freely rotating sphericallike object. We shall examine in the following the consequences of both models.

Our determination of the model parameters for $\mathrm{A}^{+Z} \cdot\left(\mathrm{NO}_{3}\right)^{-Z}$ is then completed by assuming that the values of $R_{\mathrm{X}}$ and $\rho_{\mathrm{X}}$ that we can determine on $\mathrm{RbNO}_{3}$, apply also to the other alkali nitrates, and by carrying out a self-consistent fit of the data on the infraredactive mode frequency $v_{i r}$ in the melt from the review of Brooker and Papatheodorou [10]. The results are shown in Table 1 (values given in italics in the Table are fitted to experimental data).

A main point to be noticed in Table 1 is, that the two alternative models that we are evaluating correspond to rather different values of the charge transfer from the alkali to the $\mathrm{NO}_{3}$ group. In model 2, that, as already remarked, we believe is more appropriate to alkali nitrates, a stiffer $\mathrm{NO}_{3}$ group is accompanied by an appreciably lower ionicity. We also notice that, excepting $\mathrm{LiNO}_{3}$, the value of the effective valence $Z$ is very similar for all alkalis. We therefore report in Table 2 what we believe to be our best model for $\mathrm{ANO}_{3}$ (with $\mathrm{A}=\mathrm{Na}, \mathrm{K}, \mathrm{Rb}$, and $\mathrm{Cs}$ ) corresponding to the choice $Z_{\mathrm{A}} \approx 0.63$, and the values of the A-N bond length and of the infrared-active
Table 3. Interionic force parameters in calcium nitrate and the calculated value of the $\mathrm{Ca}-\mathrm{N}$ bond length $r_{\mathrm{Ca}-\mathrm{N}}$.

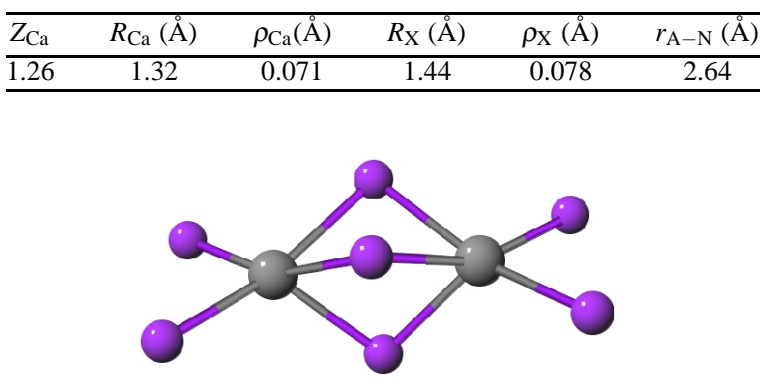

Fig. 1: Ball-and-stick model of the core structure of the $\mathrm{Ca}_{2} \mathrm{~K}_{3}\left(\mathrm{NO}_{3}\right)_{7}$ unit, showing two $\mathrm{Ca}$ ions (large balls) sharing three $\mathrm{NO}_{3}$ groups.

mode frequency that we calculate with these model parameters.

\section{Calcium Nitrate and the $\mathrm{Ca}_{2} \mathrm{~K}_{3}\left(\mathrm{NO}_{3}\right)_{7}$ Compound}

A number of divalent-metal nitrates, including $\mathrm{Ca}\left(\mathrm{NO}_{3}\right)_{2}$, crystallize in a cubic structure related to that of the typically ionic fluorite material [12]. A neutron diffraction study of $\mathrm{Pb}\left(\mathrm{NO}_{3}\right)_{2}$ as a function of temperature has given no evidence for the development of the type of hindered rotation of the nitrate ions that has been found in $\mathrm{NaNO}_{3}$.

We model the ionic interactions in $\mathrm{Ca}\left(\mathrm{NO}_{3}\right)_{2}$ by means of (1) and (2), taking the values of $R_{\mathrm{Ca}}$ and $\rho_{\mathrm{Ca}}$ from the work of Yuen et al. [19] and those of $R_{\mathrm{X}}$ and $\rho_{\mathrm{X}}$ from Table 2. Assuming $Z_{\mathrm{Ca}}=1.26$, we find that a $\mathrm{CaF}_{2}$-type linear structure with the $\mathrm{Ca}$ ion in the middle of the two groups is stable with a $\mathrm{Ca}-\mathrm{N}$ bond length of $2.64 \AA$. The values of the model parameters for calcium nitrate are collected in Table 3.

We evaluate next the equilibrium structures of the $\mathrm{Ca}_{2} \mathrm{~K}_{3}\left(\mathrm{NO}_{3}\right)_{7}$ unit, using the interionic force laws reported in Tables 2 and 3. As is shown in Fig. 1, we find a core structure in which each of the $\mathrm{Ca}$ ions is in a fivefold coordination by $\mathrm{NO}_{3}$ groups, and the two $\mathrm{Ca}$ ions share three of these $\mathrm{NO}_{3}$ groups. The Ca-N bond lengths are $2.80 \AA$ for the bonding $\mathrm{NO}_{3}$ groups and $2.76 \AA$ for the non-bonding ones. The three $\mathrm{K}$ ions can lie at several different sites around this core structure, these various configurations being all at essentially the same energy within a few hundredths of an $\mathrm{eV}$. We propose, therefore, that the structure of the CKN glass and of its melt is made from an essentially disordered spatial arrangement of the units shown in 
Fig. 1, and that the $\mathrm{K}$ ions are relatively free to transport charge by hops through such a disordered structure.

It is worth stressing that strongly bonded structural units as shown in Fig. 1 are obtained in our calculations only when we use model 2 for the alkali- $\mathrm{NO}_{3}$ interactions. In model 1 of Table 1 we find instead that the $\mathrm{Ca}$ ions are in a tetrahedral coordination and share one or at most two $\mathrm{NO}_{3}$ groups. Such structures are typical of several molten polyvalent-metal halides, for which a vitreous state cannot be reached from the melt by standard laboratory quenching techniques.

\section{Summary and Future Perspectives}

In summary, we have proposed that the structure of the CKN glass is built from strongly bonded $\mathrm{Ca}_{2}\left(\mathrm{NO}_{3}\right)_{7}$ units providing a multiplicity of sites for the $\mathrm{K}$ ions. The stability of these core units depends in a crucial manner on the nature of the nitrate group as an essentially lamellar (rather than spherical) object, and on the magnitude of the electronic charge transfer from the metal ions to the $\mathrm{NO}_{3}$ ions. Similar ideas may also be useful to describe the disordered states of other mixed-nitrate materials and of other salts such as carbonates.

[1] N.H. March and M.P. Tosi, Introduction to Liquid State Physics, World Scientific Publishing Co., Singapore 2002.

[2] C. A. Angell, Solid State Ionics 105, 15 (1998).

[3] R. Burkhalter, B. Trusch, P. Franz, A. A. Kaminskii, H. J. Eichler, and J. Hulliger, J. Mater. Chem. 11, 3211 (2001).

[4] A. Voronel, E. Veliyulin, T. Grande, and H. A. Öye, J. Phys.: Condens. Matter 9, L247 (1997).

[5] A. Voronel, E. Veliyulin, V.Sh. Machavariani, A. Kisliuk, and D. Quitmann, Phys. Rev. Lett. 80, 2630 (1998).

[6] T. Furukawa, S. A. Brawer, and W. B. White, J. Chem. Phys. 69, 2639 (1978).

[7] T. Ishiwata, I. Tanaka, K. Kawaguchi, and E. Hirota, J. Chem. Phys. 82, 2196 (1985).

[8] K. Balasubrahmanyam and G. J. Janz, J. Chem. Phys. 57, 4089 (1972).

[9] M. H. Brooker, J. Chem. Phys. 59, 5828 (1973).
A more general consequence of our calculations concerns the role of steric factors in stabilizing the vitreous state in a class of ionic materials. In recent calculations it has been estimated that unassisted Coulomb interactions may still admit the attainment of a glassy state, but at $T_{g} / T_{m}$ ratios that are extremely low for salts such as the alkali halides [11]. Supplementing Coulomb interactions with finite ionic sizes should be the first step towards a theory of glass formation in materials other than those involving network formers. Anisotropy of structural units can also be expected to play an important role. Statistical mechanical models invoking non-additivity of ionic sizes to handle strongly anisotropic ions also seem worth studying in future developments.

\section{Acknowledgements}

ZA acknowledges support from the Turkish Scientific and Technological Research Council (TUBITAK) and from the Research Fund of the University of Istanbul under Project Number UDP-154/270503. We thank A. Karaman for help in the analysis of alkali chloride molecules.

[10] M. H. Brooker and G. N. Papatheodorou, in Advances in Molten Salt Chemistry, Vol. 5, ed. G. Mamantov, Elsevier, Amsterdam 1983, p. 26.

[11] M. Cardenas and M.P. Tosi, Physica B 351, 137 (2004).

[12] R. W. G. Wyckoff, Crystal Structures, Vol. 2, Interscience, New York 1964, Chapt. VII.

[13] Z. Akdeniz and M.P. Tosi, Z. Naturforsch. 54a, 180 (1999).

[14] M. P. Tosi and F. G. Fumi, J. Phys. Chem. Solids 25, 45 (1964).

[15] M. P. Tosi and M. Doyama, Phys. Rev. 160, 716 (1967).

[16] V. A. Kulikov, V. V. Ugarov, and N. G. Rambidi, Russ. J. Struct. Chem. 22, 446 (1981).

[17] G. J. Janz, Molten Salt Handbook, Academic, New York 1967, p. 1.

[18] Z. Akdeniz, Z. Çiçek, and M.P. Tosi, Z. Naturforsch. 55a, 861 (2000).

[19] P. S. Yuen, R. M. Murfitt, and R. L. Collin, J. Chem. Phys. 61, 2383 (1974). 